\title{
Slovenian firms after privatisation: is there a transformational leadership?
}

\author{
Bruno Grancelli*
}

The issue posed by ........ concerns the influence of privatisation patterns and the competitive positions of firms. In the Slovenian case, the usual distinction in property rights applies between firms with a prevailing internal ownership and firms in which the majority of shares is held by external owners.

The Author points to the fact that in both cases the same problem is going to surface, that is, the rapid exhaustion of company resources: in one case for the pressure of Labour; in the other for the pressure of external owners. In other words, both internal and external shareholder are interested in quick returns and do not bother much about strategic issues. A difference is there, though: companies with prevailing external ownership are usually more successful while those which have not yet overcome the consequences of insiders' privatisation tend to show a picture of 'passive restructuring'.

But passive management is not the general rule, even in firms with internal ownership. As the author states, in 'particular companies' there are attempts to set in motion 'comprehensive reorganisation projects.' What does this suggest? It suggests something both on method and the object of analysis. Here I would like to put forward some quick remarks on both issues.

On the research issues. Here what is going to become clear is that the preoccupation of top management with privatisation issues has come to an end. Now it is time to address some important strategic decisions. Transformational leadership is then the issue which is coming to the fore: is there the capacity to overcome the legacy of 'socialist self-management' which, as a matter of fact, was not so different from that of Soviet management. How strong is, among Slovenian managers, the propensity towards passive adjustment to the current situation and to avoid unpopular measures? The answers to these questions imply a focus on both individual personalities and the way they cope with the internal and external environment.

On the approach. The Author concludes its paper by stating that the existing experience is not yet enough to evaluate the correlation between forms of ownership and competitivity of the firm. This may be true if one considers the

\footnotetext{
* Bruno Grancelli, Dipartimento di Sociologia e Ricerca Sociale, Università di Trento
} 
Slovenian case in isolation. But we can see that the problems referred to in this paper are not so different from those which exist in other transitional societies. Thus, if one compare the same issues in different countries one can realise that it is not premature to analyse the correlation quoted above. Of course, the experience provided by case studies is not enough per se. Some kind of theoretical framework is needed as well, if anything because we need clear criteria for assessing the relative weight of the many variables who impinge on restructuring processes and management strategies. What is worth recalling here is that the old compulsion to see theoretical work as a short-circuit of sort between interests of social groups and organizational/institutional change are of little heuristic value: at the best it can lead us to see only one side of the coin. I am referring especially to neo-Marxist approaches, some of which are now drawing insights from neo-evolutionary economics. Also inadequate, in my opinion, are other approaches which express market transition only in its structural and power dimension, such as 'local corporatism,' 'political capital,' and so on. In other words, one should not consider collective actors only but individual actors (and their networks) as well.

I agree with the Author on the fact that management style would be an interesting area of study. But the approaches referred to above (and applied to a number of case studies) are not best suited to the purpose. Other approaches centred on the concepts of 'social capital' and 'cultural capital' may be more useful, even if some problems of methods remain to be solved.

If we frame the available evidence within an adequate comparative approach, we can realise that less and less attention should be devoted to the ownership structure to focus, instead, on other discriminating variables. One of them is the branch the enterprise belongs to, because technology matters, and the issue of technological innovation/retooling of production matters most where the value of fixed assets is higher. Another important variable is the degree of diversification of the local economy, if anything because it provide managers and employees with different exit options from an unsatisfactory condition. Admittedly, regional differentiation is less important in Slovenia than, say, in Russia. Nonetheless, it would be interesting to compare the Slovenian economy with that of other regions in Central-Eastern Europe. With a caveat, though: We should not skip over issues such as the different degree of economic integration with advanced Western countries or regions.

Following this research path, the main difference to focus on is no longer that between insiders' or outsiders' ownership: It is between the $20-25 \%$ of Slovenian firms who have got some kind of partnership with Western companies and the rest. This is the main discriminating variable which explains management style. It is here that the two related concepts of social capital and cultural capital come to the fore. 
Social capital is a resource related not so much to specific know how as to a know who, that is, to the social and political networks of the individual manager. Cultural capital is linked, instead, to specific skills acquired either in learning at school or within programs of management training in the home country or abroad. Acquiring the latter kind of capital involves a process of learning and forgetting. And what is to be forgotten are the attitudes and behavioural patterns useful for a professional career within 'self-managed' economic institutions.

It is cultural capital (along with east-west business collaboration) which can pave the way organizational and economic transformation, also because the overwhelming majority of firms with export capacity have already got, I guess, external ownership. 